\title{
A escola na
}

\section{cidade que educa}

\author{
Enquanto educadora, \\ a Cidade é também educanda.
}

Paulo Freire

\section{Pode a cidade educar?}

\section{A julgar pelos que defendem o conceito e a prática da} "Cidade Educadora", a resposta é sim. Esse conceito consolidou-se no início da década de 1990, em Barcelona, na Espanha, onde se realizou o primeiro Congresso Internacional das Cidades Educadoras. Esse Congresso aprovou uma carta de princípios básicos que caracterizam uma cidade que educa. Várias cidades brasileiras são membros da Associação Internacional de Cidades Educadoras: Belo Horizonte (MG), Caxias do Sul (RS), Cuiabá (MT), Pilar (PB), Porto Alegre (RS), Piracicaba (SP), Alvorada (RS) e Campo Novo do Parecis (MT).

Foi Porto Alegre, onde nasceu o Fórum Social Mundial, que deu a partida e integrou, desde 2001, o Movimento das Cidades Educadoras, iniciando uma nova caminhada nessa associação. ${ }^{1}$ Em outros países da América Latina, várias cidades aderiram ao Movimento, entre elas, Rosário (Argentina), Concepción (Chile), Medellin (Colômbia), Santa Cruz de la Sierra (Bolívia), Quito (Equador),

* Moacir Gadotti é professor titular da Universidade de São Paulo (USP), diretor do Instituto Paulo Freire e autor, entre outras obras, de: História das idéias pedagógicas (Ática, 1993), Pedagogia da práxis (Cortez, 1994), Perspectivas atuais da educação (Artes Médicas, 2000), Pedagogia da terra (Peirópolis, 2001) e Os Mestres de Rousseau (Cortez, 2004). 
León (México), Montevidéu (Uruguai). É a cidade, como espaço de cultura, educando a escola e todos que circulam em seus espaços, e a escola, como palco do espetáculo da vida, educando a cidade numa troca de saberes e de competências.

A cidade dispõe de inúmeras possibilidades educadoras. A vivência na cidade se constitui num espaço cultural de aprendizagem permanente por si só, "espontaneamente": "há um modo espontâneo, quase como se as Cidades gesticulassem ou andassem ou se movessem ou dissessem de si, falando quase como se as Cidades proclamassem feitos e fatos vividos nelas por mulheres e homens que por elas passaram, mas ficaram, um modo espontâneo, dizia eu, de as Cidades educarem". ${ }^{2}$

Mas a cidade pode ser "intencionalmente" educadora.

Uma cidade pode ser considerada como uma cidade que educa quando, além de suas funções tradicionais - econômica, social, política e de prestação de serviços - exerce uma nova função cujo objetivo é a formação para e pela cidadania. Para uma cidade ser considerada educadora, ela precisa promover e desenvolver o protagonismo de todos - crianças, jovens, adultos, idosos na busca de um novo direito, o direito à cidade educadora: "enquanto educadora, a Cidade é também educanda. Muito de sua tarefa educativa implica a nossa posição política e, obviamente, a maneira como exerçamos o poder na Cidade e o sonho ou a utopia de que embebamos a política, a serviço de que e de quem a fazemos". ${ }^{3}$

\section{O que é educar para a cidadania?}

\section{A resposta a essa pergunta depende da resposta a} outra pergunta: o que é cidadania? Pode-se dizer que cidadania é essencialmente consciência de direitos e deveres e exercício da democracia:

- direitos civis, como segurança e locomoção;

- direitos sociais, como trabalho, salário justo, saúde, educação, habitação etc.;

- direitos políticos, como liberdade de expressão, de voto, de participação em partidos políticos e sindicatos etc.

Não há cidadania sem democracia. 0 conceito de cidadania, contudo, é um conceito ambíguo. Em 1789, a Declaração dos Direitos do Homem e do Cidadão estabelecia as primeiras normas para assegurar a liberdade individual e a propriedade. Nascia a cidadania como uma conquista liberal.
Hoje o conceito de cidadania é mais complexo. Com a ampliação dos direitos, nasce também uma concepção mais ampla de cidadania. De um lado, existe uma concepção consumista de cidadania (direito de defesa do consumidor) e, de outro, uma concepção plena, que se manifesta na mobilização da sociedade para a conquista de novos direitos e na participação direta da população na gestão da vida pública, por meio, por exemplo, da discussão democrática do orçamento da cidade.

Essa tem sido uma prática, sobretudo no nível do poder local, que tem ajudado na construção de uma democracia participativa, superando os estreitos limites da democracia puramente representativa. Adela Cortina 4 afirma que existem dimensões complementares, que se constituem em exigências de uma cidadania plena:

- cidadania política - direito de participação numa comunidade política;

- cidadania social - que compreende a justiça como exigência ética da sociedade de bem viver;

- cidadania econômica - participação na gestão e nos lucros da empresa, transformação produtiva com eqüidade;

- cidadania civil - afirmação de valores cívicos como liberdade, igualdade, respeito ativo, solidariedade, diálogo;

- cidadania intercultural - afirmação da interculturalidade como projeto ético e político frente ao etnocentrismo.

$\mathrm{Na}$ cidade que educa, todos os seus habitantes usufruem das mesmas oportunidades de formação, desenvolvimento pessoal e de entretenimento que ela oferece. O Manifesto das Cidades Educadoras aprovado em Barcelona, em 1990, e revisto em Bolonha, em 1994, afirma que "a satisfação das necessidades das crianças e dos jovens, no âmbito das competências do município, pressupõe uma oferta de espaços, equipamentos e serviços adequados ao desenvolvimento social, moral e cultural, a serem partilhados com outras gerações. 0 município, no processo de tomada de decisões, deverá levar em conta o impacto das mesmas.

A cidade oferecerá aos pais uma formação que thes permita ajudar os seus filhos a crescer e utilizar a cidade num espírito de respeito mútuo. Todos os habitantes da cidade têm o direito de refletir e participar na criação de programas educativos e culturais e a dispor dos instrumentos necessários que thes permitam descobrir um 


\section{Temos uma Escola Cidadã e uma Cidade Educadora quando existe diálogo entre a escola e a cidade.}

projeto educativo, na estrutura e na gestão da sua cidade, nos valores que esta fomenta, na qualidade de vida que oferece, nas festas que organiza, nas campanhas que prepara, no interesse que manifesta por eles e na forma de os escutar".

Nesse contexto, o conceito de "Escola Cidadã" 5 ganha um novo componente: a comunidade educadora reconquista a escola no novo espaço cultural da cidade, integrando-a a esse espaço, considerando suas ruas e praças, árvores, bibliotecas, seus pássaros, cinemas, bens e serviços, bares e restaurantes, teatros, suas igrejas, empresas e lojas... enfim, toda a vida que pulsa na cidade. A escola deixa de ser um lugar abstrato para inserir-se definitivamente na vida da cidade e ganhar, com isso, nova vida. Ela se transforma num novo território de construção da cidadania.

A relação entre Escola cidadã e Cidade Educadora encontra-se na própria origem etimológica das palavras "cidade" e "cidadão". Ambas derivam da mesma palavra latina: civis, cidadão, membro livre de uma cidade a que pertence por origem ou adoção, portanto sujeito de um lugar, aquele que se apropriou de um espaço, de um lugar. Assim, cidade (civitas) é uma comunidade política cujos membros, os cidadãos, autogovernam-se, e cidadão é a pessoa que goza do direito de cidade.

"Cidade”, "cidadão", "cidadania” referem-se a uma certa concepção da vida das pessoas, daquelas que vivem de forma "civilizada" (de civilitas, afabilidade, bondade, cortesia), participando de um mesmo território, autogovernando-se, construindo uma "civilização".

Em Roma, esse conceito de sujeito da cidade era limitado apenas a poucos homens livres, cuja cultura era o reflexo do ócio e não do trabalho. 0 trabalho era reservado aos numerosos escravos. Esses eram sujeitos "sujeitados", submetidos e, portanto, não eram considerados cidadãos, não tinham os direitos de cidadania, não eram considerados civilizados, mas estrangeiros, bárbaros, não podendo usufruir dos benefícios da civilização.
Temos uma Escola Cidadã e uma Cidade Educadora quando existe diálogo entre a escola e a cidade. Não se pode falar de Escola Cidadã sem compreendê-la como escola participativa, escola apropriada pela população como parte da apropriação da cidade a que pertence.

Nesse sentido, Escola Cidadã, em maior ou menor grau, supõe a existência de uma Cidade Educadora. Essa apropriação se dá por meio de mecanismos criados pela própria escola, como o Colegiado Escolar, a Constituinte Escolar, plenárias pedagógicas e outros. Esse ato de sujeito da própria cidade leva para dentro da escola os interesses e necessidades da população.

Esse é o "cenário" da cidade que educa, no qual as práticas escolares possibilitam qualificar o entendimento freireano tanto da leitura da palavra escrita quanto da leitura do mundo. A cidade que educa não aponta para soluções imediatas, mas para uma compreensão mais analítica e reflexiva, seja em relação aos problemas do cotidiano ou aos desafios do mundo contemporâneo.

\section{Quando a cidade educa?}

\section{0 movimento da Escola Cidadã, inicialmente muito} centrado na democratização da gestão e no planejamento participativo, aos poucos ampliou suas preocupações para a construção de um novo currículo (interdisciplinar, transdisciplinar, intercultural) e de relações sociais, humanas e intersubjetivas novas, enfrentando os graves problemas gerados pelo aumento da violência e da deterioração da qualidade de vida nas cidades e no campo.

Uma década de inovação e de experimentação, com base numa concepção cidadã da educação e de cidade educadora, foi suficiente para gerar um grande movimento, uma perspectiva concreta para a escola pública, demonstrando que a sociedade civil está reagindo à tendência oficial neoliberal, a um modelo de internacionalização da agenda da educação, que segue a mesma "receita" contida em "recomendações" de organismos internacionais, como o Banco Mundial e o FMI.

Tarso Genro ${ }^{6}$ destaca, entre as suas " 21 teses para a criação de uma política democrática e socialista”, a necessidade de uma "nova cultura política, mais abrangente, de disputa hegemônica e de incorporação de novos agentes sociais", e uma "nova esfera pública com organizações locais, regionais, nacionais e internacionais, auto-organizadas", rompendo a distância entre Estado e Cidadania. 
A Cidade Educadora é, na verdade, a realização dos objetivos do próprio planejamento urbano, que são: a "promoção e a melhoria das condições de habitat, viabilizando uma vida saudável, social, material e espiritualmente (cultura, educação e trabalho) para todos os munícipes... maior eficácia social e maior eficiência econômica do capital social, ou seja, do ambiente construído que é a cidade, distribuindo-se igualitariamente ou eqüitativamente os benefícios e o ônus dos investimentos urbanos, na perspectiva da busca da sociedade sustentável". ${ }^{7}$

\section{Quando é que podemos falar em cidade que educa?}

Podemos falar em cidade que educa quando ela busca instaurar, com todas as suas energias, a cidadania plena, ativa; quando ela estabelece canais permanentes de participação, incentiva a organização das comunidades para que elas tomem em suas mãos, de forma organizada, o controle social da cidade. Essa não é uma tarefa "espontânea" das cidades. Precisamos de vontade política e de uma perspectiva histórica. "A tarefa educativa das cidades se realiza também através do tratamento de sua memória, e sua memória não apenas guarda, mas reproduz, estende, comunica-se às gerações que chegam. Seus museus, seus centros de cultura, de arte são a alma viva do ímpeto criador, dos sinais da aventura do espírito". 8

\section{A cidade não educa sem a vontade do cidadão.}

"Por isso é importante afirmar que não basta reconhecer que a cidade é educativa, independentemente de nosso querer ou de nosso desejo. A cidade se faz educativa pela necessidade de educar, de aprender, de ensinar, de conhecer, de criar, de sonhar, de imaginar que todos nós, mulheres e homens, impregnamos seus campos, suas montanhas, seus vales, seus rios, impregnamos suas casas, seus edifícios, deixando em tudo o selo de certo tempo, o estilo, o gosto de certa época. A cidade é cultura, criação, não só pelo que fazemos nela e dela, mas pelo que criamos nela e com ela, mas também é cultura pela própria mirada estética ou de espanto, gratuita, que lhe damos. A cidade somos nós e nós somos a cidade". 9

A cidadania precisa controlar, na cidade, o Estado e o mercado, perseguindo a utopia das cidades justas, produtivas, democráticas e sustentáveis que são aquelas
Na cidade que educa, o cidadão caminha sem

\author{
medo, observando todos \\ os espaços. Temos que \\ aprender a nos locomover \\ na cidade, caminhar muito \\ por nossas ruas.
}

que conseguem "romper com o controle político das elites locais e com as formas burocráticas, corruptas e clientelistas de governar", ${ }^{10}$ e estabelecem uma nova esfera pública de decisão não-estatal, como o "orçamento participativo" e a "constituinte escolar", que já se tornaram emblemáticos nas gestões populares.

Já saímos do puro terreno das propostas nesse campo e novas experiências vêm surgindo em diversas partes do País, levadas a cabo por diferentes partidos políticos, que criam novas relações, novas formas de gestão, novos espaços de negociação e estimulam a reapropriação das cidades por seus cidadãos. E não há segredo nisso. Basta vontade política, apoiada numa ética que condene o segredo burocrático e estabeleça a transparência, que incorpore o conflito com práticas de negociação e que publicize a informação.

\section{Qual é o papel da escola na cidade que educa?}

\section{O papel da escola (cidadã), nesse contexto, é contribuir}

para criar as condições que viabilizem a cidadania, por meio da socialização da informação, da discussão, da transparência, gerando uma nova mentalidade, uma nova cultura, em relação ao caráter público do espaço da cidade.

Há uma concepção neoliberal da cidade que a considera apenas como um mercado. Nesse caso, a pedagogia neoliberal objetiva formar consumidores para o mercado. Há uma concepção emancipadora da cidade que já vem sendo defendida desde os anos 1970. Foi Edgar Faure, em seu Relatório preparado para a Unesco, no Ano Internacional da Educação (1970), e publicado em 1972 com o título "Apprendre a Être", que utiliza pela primeira vez a expressão "cidade educativa", referindo-se a um processo de "compenetração íntima" entre educação e "vida cívica". Para essa concepção da educação, o papel da escola é formar cidadãos. 


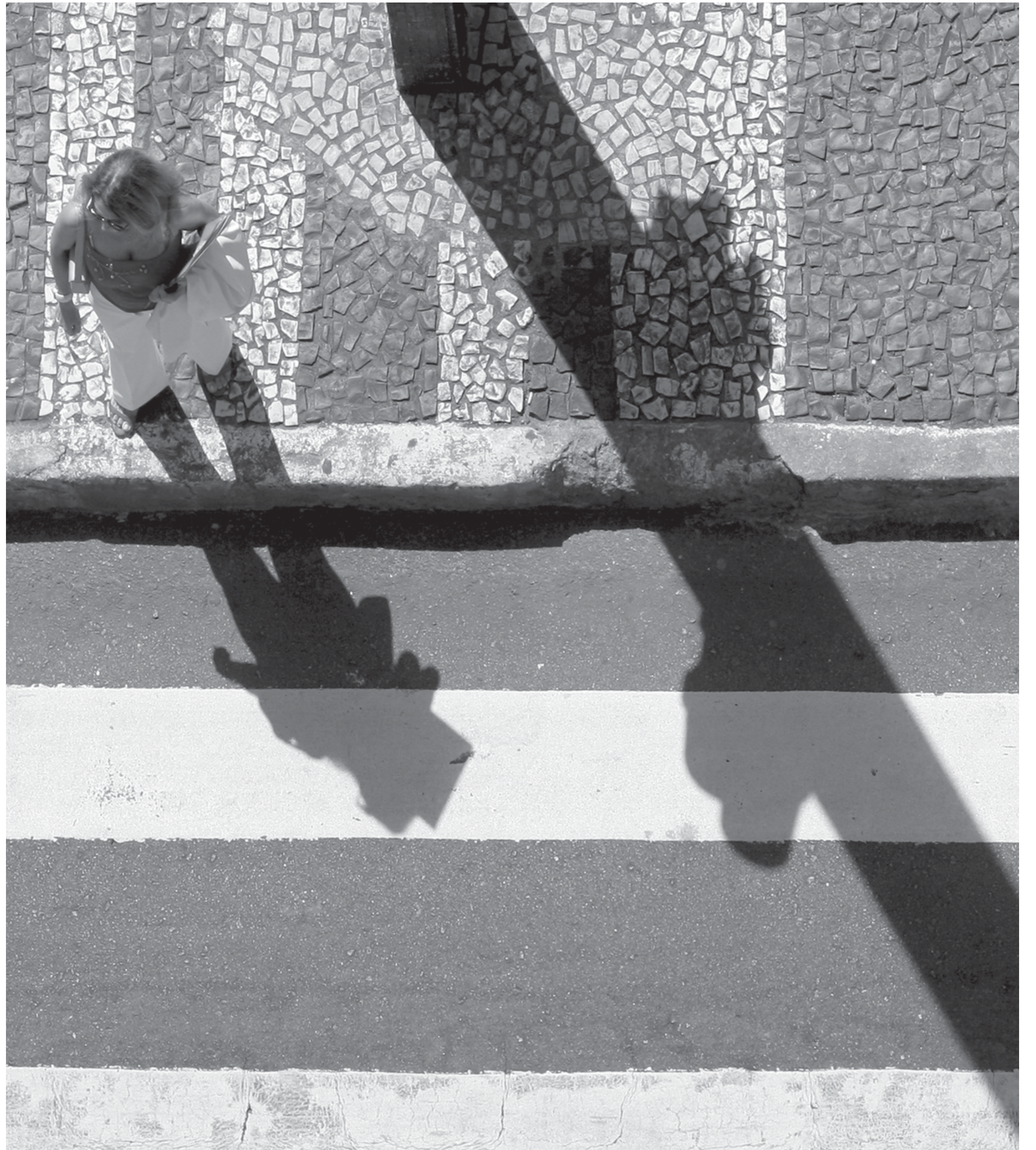


Numa perspectiva transformadora, a escola educa para ouvir e respeitar as diferenças, a diversidade que compõe a cidade e que se constitui na sua grande riqueza. O cidadão da cidade educadora presta atenção ao diferente e também ao "deficiente", ou melhor, ao portador de direitos especiais. Para que a escola seja espaço de vida e não de morte, ela precisa estar aberta para a diversidade cultural, étnica e de gênero, e às diferentes opções sexuais. As diferenças exigem uma nova escola.

\section{Escola científica e transformadora}

O grande desafio da escola numa cidade educativa é traduzir esses princípios em experiências práticas inovadoras, em projetos para a capacitação cidadã da população, para que ela possa tomar em suas mãos os destinos da sua cidade. Diante dos novos espaços de formação criados pela sociedade da informação, ela os integra e articula. Ela deixa de ser "lecionadora" para ser cada vez mais "gestora" da informação generalizada, construtora e reconstrutora de saberes e conhecimentos socialmente significativos. Portanto, seu papel é mais de articuladora da cultura, de dirigente e agregadora de pessoas, movimentos, organizações e instituições.

Na sociedade da informação, o papel social da escola foi consideravelmente ampliado. É uma escola presente na cidade e que cria novos conhecimentos, sem abrir mão do conhecimento historicamente produzido pela humanidade, uma escola científica e transformadora.

As cidades, sobretudo as grandes metrópoles, estão chegando ao limite do suportável (violência, estresse, desemprego, falta de habitação, de transporte, de saneamento...), e hoje não têm outra alternativa a não ser se transformar radicalmente em "novas cidades", em Cidades Educadoras. Caso contrário, elas estarão caminhando rapidamente para se transformar em espaços de extermínio, sobretudo dos jovens.

A educação e a cultura não podem tudo porque existem outros componentes que são os sociais, políticos e, sobretudo, econômicos. Mas a escola pode contribuir para a construção de uma sociedade saudável, tornando-se amiga e "companheira", como dizia Paulo Freire, transformando-se num espaço de formação ético-política de pessoas que se querem bem e, por isso, têm legitimidade para transformar a vida da cidade.

\section{Qual é o papel do professor na cidade que educa?}

\section{A cidade violenta e insustentável nos insere num clima}

de medo e de falta de esperança. Nossa força, como educadores e educadoras, é limitada. Nossas escolas são também produto da sociedade. Contudo, a esperança, para o professor, para a professora, não é algo vazio, de quem espera acontecer. Ao contrário, o professor encontra na esperança o sentido para a sua missão, que é a de transformar pessoas, dar-lhes nova forma, alimentando, por sua vez, as suas esperanças para que consigam construir uma realidade diferente, um mundo novo, "menos malvado, menos feio, menos autoritário, mais democrático, mais humano", ${ }^{11}$ como costumava dizer Paulo Freire. Uma educação sem esperança não é educação.

Educação, na cidade que educa, confunde-se com o próprio processo de humanização. Respondendo à questão "como o professor pode tornar-se um intelectual na sociedade contemporânea?", o grande geógrafo brasileiro Milton Santos, falecido em 2001, respondeu:

"Quando consideramos a história possível e não apenas a história existente, passamos a acreditar que outro mundo é viável. E não há intelectual que trabalhe sem idéia de futuro. Para ser digno do homem, qual seja, do homem visto como projeto, o trabalho intelectual e educacional tem que ser fundado no futuro. É dessa forma que os professores podem tornar-se intelectuais: olhando o futuro". ${ }^{12}$

\section{Para isso, precisamos de uma pedagogia da cidade.}

\section{Em primeiro lugar, precisamos aprender com a cidade.}

Paulo Freire dizia que o primeiro livro de leitura é o mundo. ${ }^{13}$ Para aprender com a cidade, precisamos ler o mundo. Em geral, nós a ignoramos, estreitamos muito nosso olhar e não a percebemos, e algumas vezes até a escondemos, damos as costas para não ver certas coisas que acontecem nela. Não queremos olhar certas coisas da cidade para não nos comprometermos com elas, pois o olhar nos compromete.

Vejamos nosso comportamento nos semáforos, quando somos abordados por meninos e meninas de rua. Nossa defesa é não olhar nos olhos deles e delas. $\mathrm{Na}$ cidade, buscamos tornar muitos seres invisiveis; isso acontece até em nossas próprias casas, quando a mostramos aos visitantes, mas não apresentamos a empregada ou a faxineira que ali trabalham. Passamos por elas como se fossem seres transparentes. 


\section{Como sujeitos da cidade,}

necessitamos nos sentir cidadãos. A cidade nos

pertence e, porque nos pertence, participamos da sua construção e da sua reconstrução permanente.

Precisamos de uma pedagogia da cidade para nos ensinar a olhar, a descobrir a cidade, para poder aprender com ela, dela, aprender a conviver com ela. A cidade é o espaço das diferenças. A diferença não é uma deficiência. É uma riqueza. Existe uma prática da ocultação das diferenças, também decorrente do medo de ser tocado por elas, sejam as diferenças sexuais, culturais etc.

Em geral, a nossa pedagogia dirige-se a um aluno médio, que é uma abstração. O nosso aluno real, contudo, o aluno concreto, é único. Cada um deles é diferente e precisa ser tratado em sua individualidade, em sua subjetividade. Uma pedagogia da cidade serve também para a escola construir o projeto político-pedagógico de uma "educação na cidade". ${ }^{14}$

$\mathrm{Na}$ cidade que educa, o cidadão caminha sem medo, observando todos os espaços. Temos que aprender a nos locomover na cidade, caminhar muito por nossas ruas. Deixar o carro em casa e caminhar. Não ver a cidade apenas por meio de fotos e vídeos. Para isso, é importante uma educação cidadã para o trânsito e para a mobilidade. Precisamos de mapas, de guias. Precisamos saber onde a gente se encontra. Como sujeitos da cidade, necessitamos nos sentir cidadãos. A cidade nos pertence e, porque nos pertence, participamos da sua construção e da sua reconstrução permanente.

Precisamos conhecer os equipamentos culturais da cidade. Qualquer programa que tenta interconectar os espaços e equipamentos é fundamental, pois desconhecemos a nossa própria cidade ou subutilizamos as suas potencialidades. Precisamos empoderar educacionalmente a todos os seus equipamentos culturais. A cidade é o espaço da cultura e da educação. Existem muitas energias sociais transformadoras que ainda estão adormecidas por falta de um olhar educativo sobre a cidade. Esse é o objeto da pedagogia da cidade.

Florestan Fernandes ${ }^{15}$ costumava repetir que a escola não educava para a cidadania, era a estrutura de poder no Brasil, arcaica e mantida pela classe dominante, que barrava a consciência crítica do povo. Essa estrutura político-social e econômica ainda é dominante. Mas a mesma sociedade que cria essa estrutura cria também a sua reação. 0 que foi socialmente construído pode ser socialmente desconstruído e reconstruído. A contradição social existe. Por isso, encontramos motivos para ser otimistas. Um deles é o surgimento de movimentos de renovação pedagógica, como o da Escola Cidadã e o da Cidade Educadora. Eles não têm apenas a mesma identidade do ponto de vista etimológico. Eles apontam para o mesmo projeto de futuro, para a construção de uma sociedade educadoraeducanda, humanizada, emancipada e solidária.

\section{Notas e referências bibliográficas}

1 Sobre o conceito e a experiência das "Cidades educadoras", veja: GADOTTI, Moacir; PADILHA Paulo Roberto; CABEZUDO, Alicia. Cidade educadora: princípios e experiências. São Paulo: Cortez/ IPF, 2004. E, também, TOLEDO, Leslie; FLORES, Maria Luiz Rodrigues e CONZATTI, Marli. Cidade educadora: a experiência de Porto Alegre. São Paulo: Cortez/IPF, 2004.

2 FREIRE, Paulo. Política e educação. São Paulo: Cortez, 1993, p. 23. 3 FREIRE, Paulo, 1993, p. 23.

4 CORTINA, Adela. Ciudadanos del mundo: hacia una téoria de la ciudadanía. Madrid: Alianza, 1997.

5 Em 1993, o Centro de Pesquisas para Educação e Cultura de São Paulo (CENPEC), com o apoio do Unicef, escolheu 15 experiências significativas de municípios, cujas políticas educacionais promoviam "a democratização da gestão escolar com participação da comunidade para fortalecê-la como o centro das decisões" (CENPEC. A democratização do ensino em 15 municípios brasileiros. São Paulo: Cenpec/Unicef, 1993, p. 13). Essas experiências revelaram um novo movimento de inovação na base da sociedade, ainda no final da década de 1980, precedendo o movimento pela Escola Cidadã do início dos anos 1990.

6 GENRO, Tarso. 0 novo espaço público: 21 teses para a criação de uma política democrática e socialista. Caderno Mais, Folha de $S$. Paulo, 9/6/1996.

7 CARVALHO, Pompeu Figueiredo de. In: BRAGA, Roberto; CARVALHO, Pompeu Figueiredo de (orgs.). Estatuto da cidade: política urbana e cidadania. Rio Claro: Unesp, 2000, p. 42.

8 FREIRE, Paulo. Política e educação. São Paulo: Cortez, 1993, p. 24.

9 FREIRE, Paulo, 1993, p. 22.

10 BAVA, Sílvio Caccia. A reapropriação das cidades. Cadernos Le Monde Diplomatique, Porto Alegre, Fórum Social Mundial, 2001, p. 18.

11 GADOTTI, Moacir; ROMÃO, José E. (Orgs). Educação de jovens e adultos: teoria, prática e proposta. 2. ed. ver. São Paulo: Cortez/ Instituto Paulo Freire, 2000, p. 17 (Guia da escola cidadã, v. 5).

12 SANTOS, Milton. O professor como intelectual na sociedade contemporânea. In: Anais do IX - Encontro Nacional de Didática e Prática de Ensino (Endipe). v. III. São Paulo: 1999, p. 14.

13 FREIRE, Paulo; MACEDO, Donaldo. Alfabetização: leitura da palavra, leitura do mundo. Rio de Janeiro: Paz e Terra, 1990.

14 Em 1991, refletindo sobre suas propostas para a cidade de São Paulo, Paulo Freire escreveu um belo livro com esse título (Educação na cidade. São Paulo: Cortez, 1991).

15 GADOTTI, Moacir. Uma só escola para todos: caminhos da autonomia escolar. Petrópolis, RJ: Vozes, 1990. 